\title{
A highly sensitive and selective viral protein detection method based on RNA oligonucleotide nanoparticle
}

This article was published in the following Dove Press journal:

International Journal of Nanomedicine

21 April 2010

Number of times this article has been viewed

\section{Changhyun Roh' \\ Ho-Young Lee ${ }^{2}$ \\ Sang-Eun Kim ${ }^{2}$ \\ Sung-Kee Jo'}

'Radiation Research Division for Biotechnology, Advanced Radiation Technology Institute (ARTI), Korea Atomic Energy Research Institute (KAERI), Sinjeong-dong, Jeongeup, Jeonbuk, South Korea; ${ }^{2}$ Department of Nuclear Medicine, College of Medicine, Seoul National University, South Korea
Correspondence: Changhyun Roh Radiation Research Division for Biotechnology, Advanced Radiation Technology Institute (ARTI), Korea Atomic Energy Research Institute (KAERI), I266, Sinjeong-dong, Jeongeup, Jeonbuk 580-185, South Korea

Tel +82 635703227

Fax +82635703229

Email chroh@kaeri.re.kr

Sung-Kee Jo

Radiation Research Division for Biotechnology, Advanced Radiation Technology Institute (ARTI), Korea Atomic Energy Research Institute (KAERI), I 266, Sinjeong-dong, Jeongeup, Jeonbuk 580-185, South Korea

$\mathrm{Tel}+82635703200$

Fax +82635703229

Email skjo@kaeri.re.kr
Abstract: Globally, approximately 170 million people (representing approximately $3 \%$ of the population worldwide), are infected with hepatitis $\mathrm{C}$ virus (HCV) and at risk of serious liver disease, including chronic hepatitis. We propose a new quantum dots (QDs)-supported RNA oligonucleotide approach for the specific and sensitive detection of viral protein using a biochip. This method was developed by immobilizing a HCV nonstructural protein 5B (NS5B) on the surface of a glass chip via the formation of a covalent bond between an amine protein group and a ProLinker ${ }^{\mathrm{TM}}$ glass chip. The QDs-supported RNA oligonucleotide was conjugated via an amide formation reaction from coupling of a $5^{\prime}$-end-amine-modified RNA oligonucleotide on the surface of QDs displaying carboxyl groups via standard EDC coupling. The QDs-conjugated RNA oligonucleotide was interacted to immobilized viral protein NS5B on the biochip. The detection is based on the variation of signal of QDs-supported RNA oligonucleotide bound on an immobilized biochip. It was demonstrated that the value of the signal has a linear relationship with concentrations of the HCV NS5B viral protein in the $1 \mu \mathrm{g} \mathrm{mL}^{-1}$ to $1 \mathrm{ng} \mathrm{mL}^{-1}$ range with a detection limit of $1 \mathrm{ng} \mathrm{mL}^{-1}$. The major advantages of this RNA-oligonucleotide nanoparticle assay are its good specificity, ease of performance, and ability to perform one-spot monitoring. The proposed method could be used as a general method of HCV detection and is expected to be applicable to other types of diseases as well.

Keywords: hepatitis C virus, viral protein, RNA oligonucleotide, quantum dots, biochip

\section{Introduction}

Hepatitis $\mathrm{C}$ virus (HCV) is a major human health problem worldwide which can result in acute and chronic hepatitis, cirrhosis, and/or development of hepatocellular carcinoma. ${ }^{1,2} \mathrm{HCV}$ is a single-stranded positive sense RNA virus, the $9.6 \mathrm{~kb}$ genome of which is organized to contain a single, large translational open-reading frame that encodes a large polyprotein precursor (3010-3030 amino acids). ${ }^{3,4}$ The genome is replicated via a negative-stranded intermediate by the nonstructural protein $5 \mathrm{~B}$ (NS5B), that is viral RNA-dependent RNA polymerase, a crucial and unique component of viral replication machinery. ${ }^{5-15}$ Because of its essential role in viral replication, HCV NS5B viral protein is regarded as a prime target for antiviral therapy.

There has been considerable interest in the development of simple and reliable methods for detection of HCV for applications in diagnostic medicine. Presently, the most widely used method for diagnosing $\mathrm{HCV}$ is the detection of anti-HCV antibodies using a screening enzyme-linked immunosorbent assay (ELISA), based on recombinant proteins from the genome of $\mathrm{HCV} .{ }^{16,17}$ Although it is highly specific, this assay has limitations. For example, it cannot detect viruses during the early stage 
of infection, at a time when antibodies against HCV antigens are not yet produced. The ELISA method sometimes generates false-positive or false-negative results. ${ }^{18}$ In addition, antibody use is temperature-sensitive, has specific reaction conditions, and requires a secondary antibody conjugated with enzyme and fluorescent dyes.

Quantum dots (QDs), which are colloidal nanoparticles of semiconductor materials with a $\mathrm{CdSe} / \mathrm{ZnS}$ core shell, have attracted considerable attention in the fields of nanotechnology and biotechnology, especially influorescence-based biological imaging applications. ${ }^{19-23}$ Semiconductor QDs possess remarkable optical characteristics compared with conventional organic fluorophores in terms of being bright, tunable, and having narrow fluorescence emission, as well as broad absorption spectra. ${ }^{24-26}$

Recently, there have been many studies on the development of fluorescence-based assays for HCV RNA detection. ${ }^{27,28}$ Furthermore, a variety of assay methods have been developed for the qualitative and quantitative detection of HCV. Among the developed methods, biosensors based on RNA-oligonucleotide nanoparticles have attracted significant attention and are a promising method for specific detection of oligonucleotide because of their high sensitivity, low cost, rapid response, portability (compatibility for miniaturization), and low labor requirement. Several papers have been published on RNA biosensors for HCV detection, ${ }^{29,30}$ however, to date, little has been reported on HCV viral protein detection using QDs-supported RNA oligonucleotide. Driven by the need to detect the presence of the HCV disease, herein it was demonstrated for the first time that RNA oligonucleotide with functional signal sequence could be used for screening and quantifying $\mathrm{HCV}$ viral protein with selectivity and sensitivity. It is shown here that QDs-conjugated RNA oligonucleotide could be used as a probe for the detection of HCV viral protein using biochip.

\section{Materials and methods}

\section{Materials}

EDC ( $N$-(3-dimethylaminopropyl)- $N$ 'ethylcarbodiimide hydrochloride), bovine serum albumin (BSA) and kanamycin were purchased from Sigma-Aldrich Chemical Co. (St. Louis, MO). Quantum dots (QDs) was purchased from Invitrogen Corporation (Carlsbad, CA). The Prolinker ${ }^{\mathrm{TM}}$-terminated glass slide was purchased from Proteogen (Seoul, Republic of Korea). All other chemicals were of the highest grade.

\section{Conjugation of quantum dots and RNA oligonucleotide}

An amine group with a terminal modification of NS5B RNA oligonucleotide (NS5Bnor) and NS5B RNA oligonucleotide mutant (NS5Bmut) were synthesized by BIONEER Co. Ltd. (Seoul, Republic of Korea) and carboxylterminated QDs525 was purchased from Invitrogen (Calsbad, CA). The amino group of NS5B RNA oligonucleotide (NS5Bnor: H2N-5'-GGCCACAUUGUGAGGGGCUC-3') and unspecific oligonucleotide (NS5Bmut: H2N-5'CCCCACAUUCUCACCCCCUC-3') used as a mutant of NS5B RNA oligonucleotide were first covalently conjugated onto the surface of the carboxyl-terminated QDs (10 pM, $1.25 \mu \mathrm{L})$. That is, $10 \mathrm{pM}$ of QDs were conjugated with $400 \mathrm{pM}$ of oligonucleotide with EDC $40 \mathrm{nM}, 1 \mu \mathrm{L}$ to activate amide bond formation to produce QDs-conjugated oligonucleotide (QDs-NS5B oligonucleotide) at a QDs:RNA oligonucleotide molar ratio of 1:40 for one hour at room temperature. Thereafter, QDs-oligonucleotide conjugate was collected using a centrifugal filtration at 15,000 rpm for 30 minutes, followed by several washing steps with a Tris buffer $(50 \mathrm{mM}$ Tris- $\mathrm{HCl}$ $\mathrm{pH} 7.4,5 \mathrm{mM} \mathrm{KCl}, 100 \mathrm{mM} \mathrm{NaCl}, 1 \mathrm{mM} \mathrm{MgCl}$, and $0.1 \%$ $\mathrm{NaN}_{3}$ ). After centrifugal filtration and washing, the pellet of QDs-conjugated RNA oligonucleotide was dispersed by brief sonication $(22 \mathrm{kHz}$, amplitude $12 \mu \mathrm{m}$, and sonication time 120 seconds) using a sonic dismembrator (Model F60 Sonic Dismembrator; Fisher Scientific, Fair Lawn, NJ).

\section{Subcloning, expression, and purification of viral protein}

The gene was amplified by a PCR with the primer set, sense: 5'-CGCGAATTCATGTCCTACACATGGACAGG3'; antisense: 5'-TTTCTCGAGTCGGTTGGGGAGCAGGTA-3', containing restriction enzyme sites of EcoRI/XhoI. PCR was run with the following conditions on a thermal cycler: denaturation at $94^{\circ}$ for one minute, annealing at $62^{\circ}$ for 30 seconds, and extension at $72^{\circ}$ for 2.5 minutes. The sequence was repeated 35 times followed by a seven-minute final extension step at $72^{\circ}$. The PCR product was digested with $E c o \mathrm{RI} / X h o \mathrm{I}$, and then ligated into a $E c o \mathrm{RI} / X h o \mathrm{I}$ digested expression vector pET 28a+ (Novagen, Madison, WI), and transformed into Escherichia coli DH5 $\alpha$ (Stratagene, La Jolla, CA). The correct colony transformed with an insert gene, and was then transformed into E. coli BL21 (DE3) (Stratagene, La Jolla, CA) and plated on Luria-Bertani (LB) agar containing $50 \mu \mathrm{g} \mathrm{mL}^{-1}$ kanamycin. The transformant was grown in a $250 \mathrm{~mL}$ flask containing $50 \mathrm{~mL} \mathrm{LB}$ medium 
supplemented with $50 \mu \mathrm{g} \mathrm{mL} \mathrm{m}^{-1}$ of kanamycin at $37^{\circ}$ until the cell concentration reached an $\mathrm{OD}_{600 \mathrm{~nm}}$ of 0.6 , and isopropyl-thio- $\beta$-D-galactopyranoside (IPTG) at a final concentration of $0.1 \mathrm{mM}$, followed by overnight growth at $25^{\circ} \mathrm{C}$ with shaking at $180 \mathrm{rpm}$. Cells were harvested by centrifugation at $4000 \mathrm{rpm}$ for 30 minutes at $4^{\circ} \mathrm{C}$ and resuspended in $100 \mathrm{mM}$ potassium phosphate buffer $(\mathrm{pH} 7.5)$ containing $1 \mathrm{mM}$ phenylmethylsulfonyl fluoride (PMSF). Cells were lysed by sonic dismembrator. The cell debris was removed by centrifugation at 15,000 rpm for 30 minutes. The supernatant was collected and the recombinant protein was purified using a Ni-nitrilotriacetic acid (Ni-NTA) affinity chromatography column (Qiagen, Hilden, Germany). The supernatant was equilibrated with buffer A (10 mM Tri-HCl, $500 \mathrm{mM} \mathrm{NaCl}, 5 \mathrm{mM}$ imidazole, $\mathrm{pH}$ 8.0). The bound protein was eluted with buffer B (10 mM Tris- $\mathrm{HCl}, 500 \mathrm{mM} \mathrm{NaCl}$, $500 \mathrm{mM}$ imidazole, $\mathrm{pH} 8.0$ ) at $4^{\circ}$. Purity of the protein was estimated by sodium dodecyl sulfate polyacrylamide gel electrophoresis (SDS-PAGE) in the eluted fractions, using $10 \%$ polyacrylamide running gels. ${ }^{31}$ The purity of the enzyme was estimated by SDS-PAGE. The protein concentration was determined as described by Bradford ${ }^{32}$ with a BSA as standard. Enzyme samples were supplemented with 50\% glycerol and stored at $-20^{\circ} \mathrm{C}$ until use.

\section{Electron microscopy}

The free QDs and QD-conjugated RNA oligonucleotide were dried on a carbon Formvar-coated 200-mesh nickel grid, and were analyzed by transmission electron microscopy (TEM) (JEM-1400, JEOL Tokyo, Japan). The analysis of TEM was done at $80 \mathrm{kV}$.

\section{Fluorescence microscopy}

The recombinant $\mathrm{HCV}$ viral protein was immobilized directly onto the functional ProLinker-terminated surface. For the targeting of the specific RNA oligonucleotide, the QDs-conjugated RNA oligonucleotide was facilitated by spotting on immobilized HCV viral protein glass chip. After incubation for one hour at $25^{\circ} \mathrm{C}$, the glass chip was then washed three times with the phosphate buffer $(\mathrm{pH}$ 7.2) for one minute. The glass chip was analyzed by a confocal laser scanning microscope LSM 510 META (Carl Zeiss, Jena, Germany). The signal intensity was determined by software for the LSM510 (LSM Image Browser). A histogram of the intensity was obtained from the region of the spotted chip. The value of the signal intensity was obtained by calculating and expressing it as the mean intensity.

\section{Results and discussion}

\section{Schematic outline of the biochip}

The biochip, a solid-phase assay method to investigate protein-RNA interaction, is becoming an attractive tool in biotechnology today for diagnostic and therapeutic purposes as well as for basic research. We designed a highly sensitive biochip using a ProteoChip coated with ProLinker, a novel calixcrown derivative with a bifunctional coupling property that permits efficient immobilization of captured viral protein on solid matrices and makes a simple analysis of protein-RNA interactions possible. ${ }^{33}$ Specific detection of the viral protein was demonstrated by QDs-conjugated RNA oligonucleotide on the biochip. The full procedure for detection on biochip is as follows. First, the viral protein was spotted on a glass chip with carboxyl as the functional

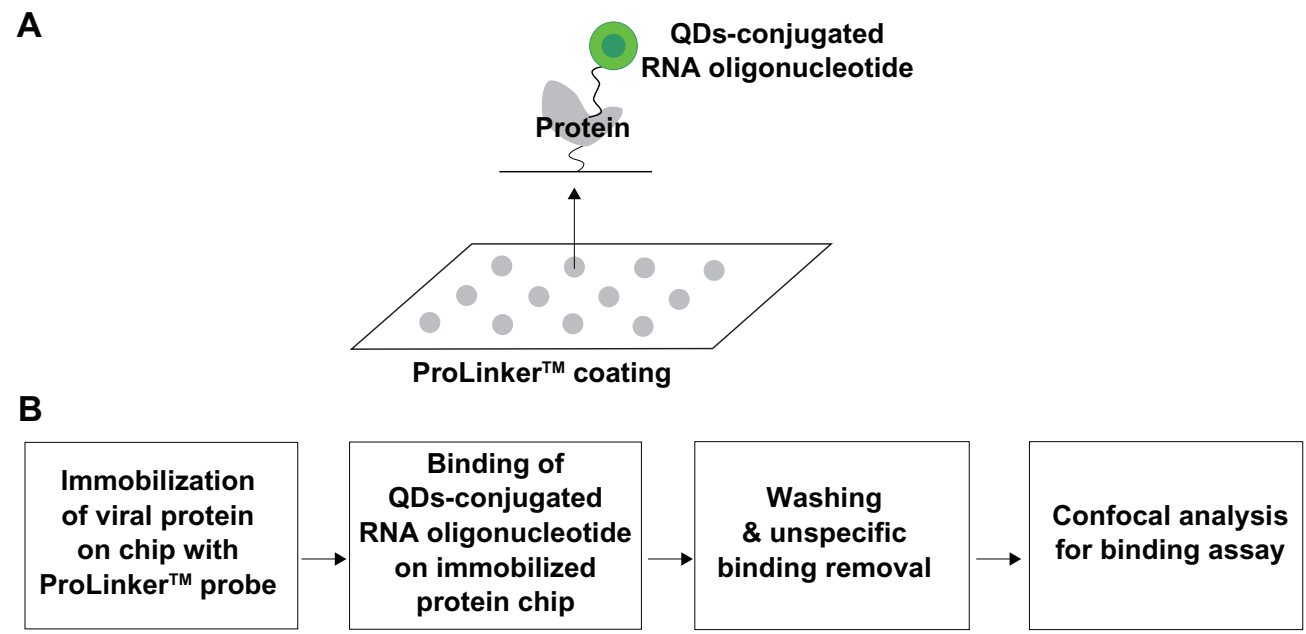

Figure I Representative scheme for the detection of viral protein on chip. A) Scheme for viral protein assay on chip. B) Procedure for viral protein assay. 
group. Second, the QDs-conjugated RNA oligonucleotide was bound on an immobilized chip. Third, the bound chip was washed to remove nonspecific binding. Fourth, it was analyzed to identify the specific detection of viral protein on the biochip. The targeting process for effective monitoring of the viral protein on the biochip is illustrated in Figure 1. Feasibility of targeting and imaging was achieved by using QDs525 conjugates containing RNA oligonucleotide for specific NS5B viral protein.

\section{QDs-conjugated RNA oligonucleotide}

The QDs-supported RNA oligonucleotide was conjugated via amide formation from coupling of the 5'-endamine-modified RNA oligonucleotide at the surface of QDs displaying carboxyl groups via standard EDC coupling. Formation of the QDs-conjugated RNA oligonucleotide was confirmed on $2 \%$ agarose gel at $100 \mathrm{~V}$ in Tris-acetateEDTA buffer. Agarose gel electrophoresis showed a distinct mobile band pattern between the free QDs and the QDs-conjugated RNA oligonucleotide, confirming the formation of QDs-conjugated RNA oligonucleotide. The mobility shifts are compared in Figure 2. On agarose gel, both the QDs-conjugated NS5Bnor RNA oligonucleotide and the NS5Bmut oligonucleotide showed less mobility shift

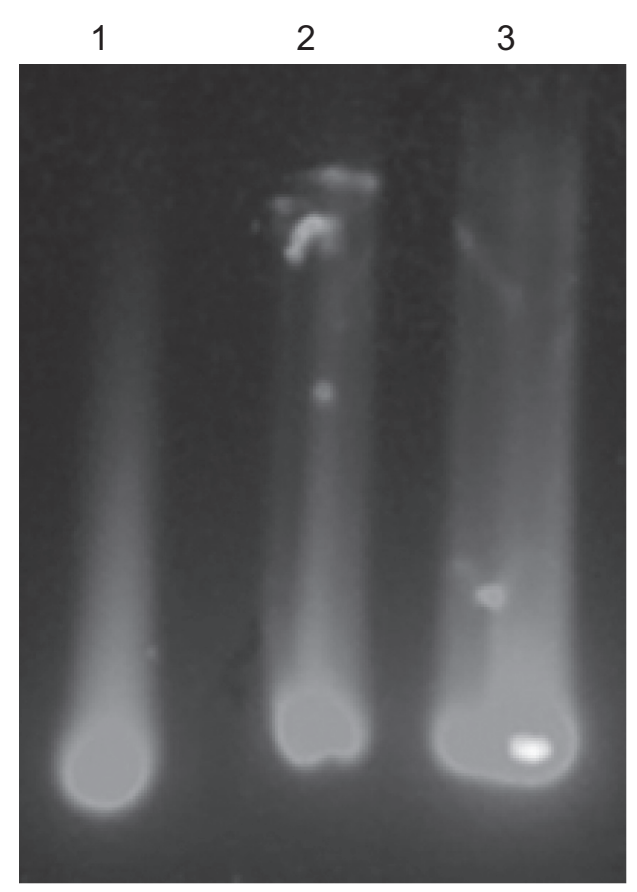

Figure 2 The conjugation pattern on $2 \%$ agarose gel electrophoresis was examined at UV excitation wavelength (345 nm), free QDs (lane I), QDs-NS5Bnor RNA oligonucleotide (lane 2), and QDs-NS5Bmut RNA oligonucleotide (lane 3). Carboxyl-terminated QDs are conjugated with RNA oligonucleotide by an amine-carboxyl reaction.

Abbreviations: NS5B, nonstructural protein 5B; QDs, quantum dots; UV, ultraviolet.
A

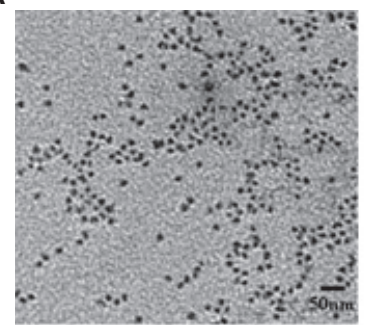

B

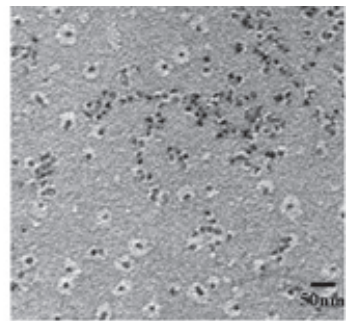

Figure 3 Characterization of QDs byTEM analysis. A) Free QDs. B) QDs-conjugated RNA oligonucleotide.

Abbreviations: QDs, quantum dots; TEM, transmission electron microscopy.

than free QDs, thereby demonstrating conjugation by amide formation between the QDs and RNA oligonucleotide.

By TEM, both the QDs and the QDs-conjugated RNA oligonucleotide appeared spherical and fairly monodispersed (Figure 3). In Figure 3A, only the free QDs nanoparticles are visible. In addition, the nanoparticles appeared to be evenly distributed on the surface. Both the QDs and the RNA oligonucleotide were conjugated in the EDC coupling reaction. The QDs (dark spot) was surrounded by a white disk of conjugated RNA oligonucleotide (Figure 3B).

\section{Detection of viral protein on biochip}

The recombinant HCV NS5B viral protein in the E. coli expression system was expressed and purified by Ni-NTA affinity chromatography. In the purification step, the protein was eluted in $1 \mathrm{~mL}$ fractions with $250 \mathrm{mM}$ imidazole buffer. To verify the purity and homogeneity of the eluted NS5B, aliquots of eluted fractions were analyzed by Coomassie blue staining on SDS-PAGE. Eluates with a purity of $95 \%$ were pooled, dialyzed and stored with $50 \%$ glycerol in aliquots at $-80^{\circ} \mathrm{C}$. The HCV NS5B viral protein was purified by a single chromatography step on a $\mathrm{Ni}^{2+}$ affinity column. The C-terminally his-tagged HCV NS5B was visualized with a molecular mass of approximately $66 \mathrm{kDa}$ on SDS-PAGE (Figure 4).

We demonstrated the specific interaction between QDsconjugated RNA oligonucleotide and immobilized HCV NS5B viral protein on a chip. As illustrated in Figure 5A, the QDs-NS5Bnor RNA oligonucleotide-treated conjugates showed high fluorescent signals on the chip. In Figure 5B, no fluorescence signal was detected with a NS5Bmut RNA oligonucleotide, because of its lack of affinity. The signal of QDs-conjugated NS5Bmut RNA oligonucleotide for proteinbinding affinity was very similar to the background signal. Figure 5C shows that QDs-conjugated RNA oligonucleotide is selective for HCV NS5B viral protein at varying protein concentrations. The binding affinity by confocal assay with varying concentrations of the NS5B viral protein was exam- 


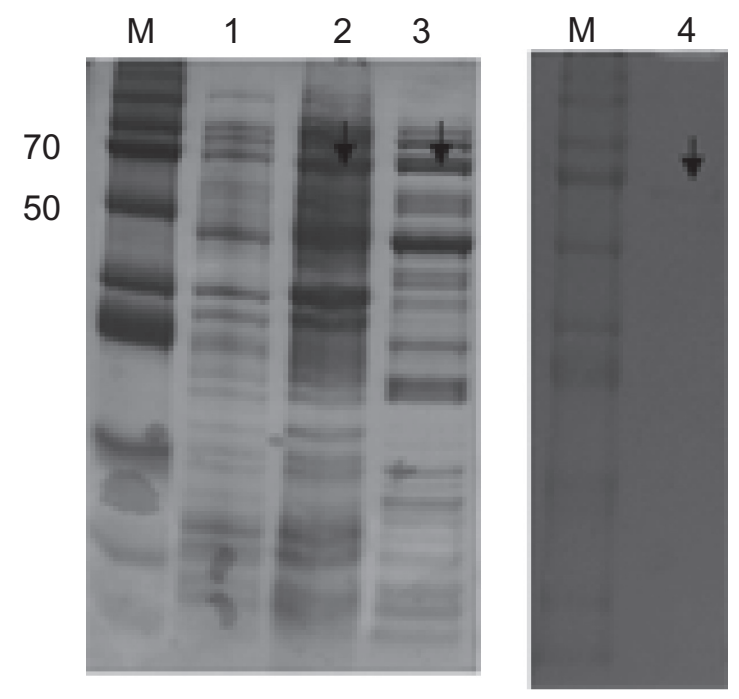

Figure 4 Purification of HCV-NS5B viral protein. The SDS-PAGE 10\% gel showing NS5B protein with his-tag. M, protein marker; lane I, before induction form of NS5B; lane 2, total form of NS5B; lane 3, soluble form of NS5B; lane 4, his-Tag form of NS5B.

Abbreviations: $\mathrm{HCV}$, hepatitis $\mathrm{C}$ virus; NS5B, non-structural protein 5B; SDS-PAGE, sodium dodecyl sulfate polyacrylamide gel electrophoresis.

ined, and it was observed that the signal intensity of the QDsconjugated RNA oligonucleotide could be detected even at

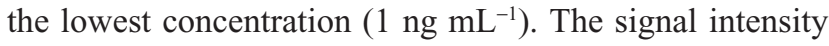
was found to increase gradually by up to $1 \mathrm{ng} \mathrm{mL}^{-1}$ of protein concentration. The insert figure in Figure 5D shows that the detection limit of this method was at the $1 \mathrm{ng} \mathrm{mL}{ }^{-1}$ level.

These results suggest the NS5B RNA oligonucleotide could specifically target the HCV NS5B viral protein on an immobilized chip. These results show that the QDs-RNA oligonucleotide could be effective for the quantification of HCV NS5B viral protein. To confirm a competition reaction of specific binding, BSA was used as a negative control protein. No fluorescence signal was detected with BSA (data not shown). Using the QDs-RNA oligonucleotide, we developed a HCV biosensor prototype biochip that could detect and quantify the HCV NS5B viral protein. Here, the specific RNA oligonucleotide was examined for binding to the HCV NS5B viral protein by using a QDs-conjugated imaging system. HCV-specific targeting and imaging using a QDs-conjugated RNA oligonucleotide agent was demonstrated. Preferential binding of QDs-conjugated RNA oligonucleotide for detection of HCV NS5B viral protein was determined by analyzing fluorescence intensity measured by confocal microscopy. The immobilized protein chip showed no binding to NS5Bmut RNA oligonucleotide, thus demonstrating selectivity for HCV NS5B viral protein. Imaging by semiconductor nanocrystal QDs allows for monitoring with intense light emission and accuracy.
A

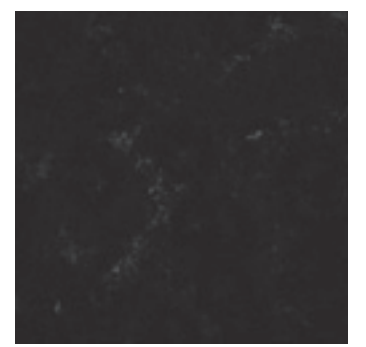

NS5Bnor RNA oligonucleotide

B

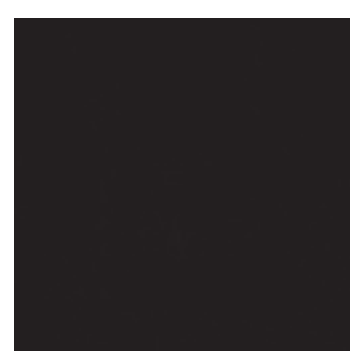

NS5Bmut RNA oligonucleotide
C

$\left(\mu \mathrm{g} \mathrm{mL}^{-1}\right) \quad 0.0010 .010 .050 .1 \quad 0.5 \quad 1.0$

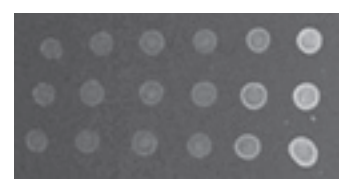

NS5Bnor RNA oligonucleotide

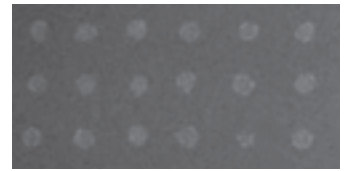

D

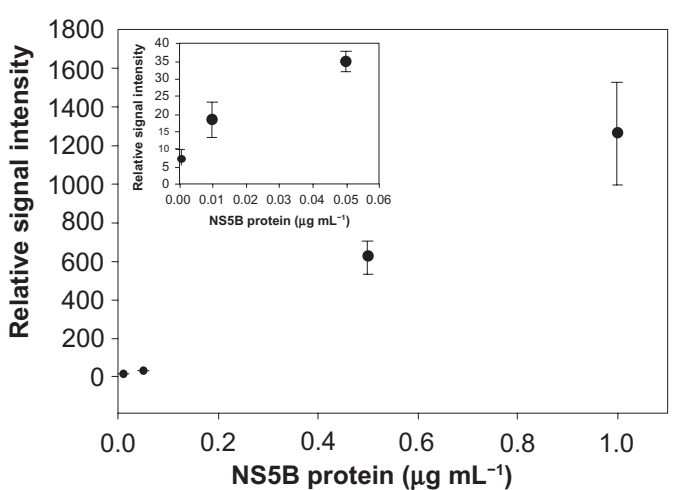

Figure 5 A, B) Selective specificity of HCV-NS5B viral protein by QDs-conjugated RNA oligonucleotide. The NS5Bnor and NS5Bmut RNA oligonucleotides were bound on an immobilized viral protein chip, respectively. C, D) Effect of HCV-NS5B viral protein concentrations on binding assay.

Abbreviations: HCV, hepatitis C virus; NS5B, non-structural protein 5B; NS5Bnor, normal NS5B; NS5Bmut, mutant NS5B; QDS, quantum dots. 
During the last decade, there has been an increasing interest in using nanoparticles in biologic applications. The availability of colloidal semiconductor QDs with highly controlled optical properties in the nanometer size range has created widespread interest in the use of biotechnologic systems as a diagnostic platform and for biologic imaging. In this study, we report a QDs-conjugated RNA oligonucleotide probe for screening of HCV with high sensitivity and selectivity.

A RNA oligonucleotide sensor system that could quantify HCV NS5B viral protein using conjugated QDs-RNA oligonucleotide could provide an efficient strategy and a promising new platform for monitoring applications.

In summary, we have shown that QDs-RNA oligonucleotide can specifically recognize the $\mathrm{HCV}$ viral protein, and have demonstrated that this conjugated QDs-RNA oligonucleotide can interact on a designed biochip specifically and sensitively. This device could generate a QDs-conjugated biosensor prototype biochip for HCV diagnosis. The present visual $\mathrm{HCV}$ detection technique may avoid the limitations with its reported methods, namely, its high sensitivity, good specificity, simplicity, speed, and cost-effectiveness. This technique has potential applications in many fields, especially in multiple virus detection chip coupled with nanoparticle will find applications in clinic.

\section{Conclusions}

The results of this study indicate that the QDs-conjugated RNA oligonucleotide can recognize the $\mathrm{HCV}$ viral protein

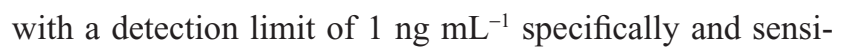
tively on a designed biochip. This device could generate a nanoparticle-conjugated prototype biochip for $\mathrm{HCV}$ diagnosis.

\section{Acknowledgments}

We thank Professor Dr Myung Heejoon and Professor Dr Seong-Wook Lee for their very kind donation of plasmid pCite. This work was supported by SNU-KAERI Degree and Research Center for Radiation Convergence Sciences from the Korea Research Council of Foundation (KRCF) Science and Technology, South Korea.

\section{Disclosures}

The authors report no conflicts of interest in this work.

\section{References}

1. Weiss U. Hepatitis. Nature. 2005;436:929.

2. Jameel S, Siddiqui A, Hu KQ. The molecular biology of hepatitis virus. In: Gitnick G, editor. Principles and Practice of Gastroenterology and Hepatology. New York, NY: Elsevier; 1994. p. 743-757.
3. Pawlotsky JM. Hepatitis $\mathrm{C}$ virus population dynamics during infection. Curr Top Microbiol Immunol. 2006;299:261-284.

4. Reed KE, Rice CM. Overview of hepatitis C virus genome structure, polyprotein processing, and protein properties. Curr Top Microbiol Immunol. 2000;242:55-84.

5. De Francesco R, Tomei L, Altamura S, et al. Approaching a new era for hepatitis C virus therapy: Inhibitors of the NS3-4A serine protease and the NS5B RNA-dependent RNA polymerase. Antiviral Res. 2003;58:1-16.

6. Behrens SE, Tomei L, De Francesco R. Identification and properties of the RNA-dependent RNA polymerase of hepatitis $\mathrm{C}$ virus. EMBO J. 1996; 15:12-22.

7. Adachi T, Ago H, Habuka N, et al. The essential role of C-terminal residues in regulating the activity of hepatitis $\mathrm{C}$ virus RNA-dependent RNA polymerase. Biochim Biophys Acta. 2002;1601:38-48.

8. Ferrari E, Wright-Minogue J, Fang JW, et al. Characterization of soluble hepatitis C virus RNA-dependent RNA polymerase expressed in Escherichia coli. J Virol. 1999;73:1649-1654.

9. Yamashita T, Kaneko S, Shirota Y, et al. RNA-dependent RNA polymerase activity of the soluble recombinant hepatitis $\mathrm{C}$ virus NS5B protein truncated at the C-terminal region. J Biol Chem. 1998;273:15479-15486.

10. Ishii $\mathrm{K}$, Tanaka $\mathrm{Y}$, Yap CC, et al. Expression of hepatitis C virus NS5B protein: Characterization of its RNA polymerase activity and RNA binding. Hepatology. 1999;29:1227-1235.

11. Ago H, Adachi T, Yoshida A, et al. Crystal structure of the RNAdependent RNA polymerase of hepatitis C virus. Structure. 1999;7: 1417-14126.

12. Bressanelli S, Tomei L, Roussel A, et al. Crystal structure of the RNAdependent RNA polymerase of hepatitis C virus. Proc Natl Acad Sci US A. 1999;96:13034-13039.

13. Lohmann V, Overton H, Bartenschlager R. Selective stimulation of hepatitis $\mathrm{C}$ virus and pestivirus NS5B RNA polymerase activity by GTP. J Biol Chem. 1999;274:10807-10815.

14. Dhanak D, Duffy KJ, Johnston VK, et al. Identification and biological characterization of heterocyclic inhibitors of the hepatitis $\mathrm{C}$ virus RNAdependent RNA polymerase. J Biol Chem. 2002;277:38322-38327.

15. Neerja KB, Alain BW, Tanaji TT, et al. Identification and characterization of coumestans as novel HCV NS5B polymerase inhibitors. Nucl Acids Res. 2008;36:1482-1496.

16. Cullen BR. Immunology. Outwitted by viral RNAs. Science. 2007; 317:329-330.

17. Griffin J, Singh AK, Senapati D, et al. Size- and distance-dependent nanoparticle surface-energy transfer (NSET) method for selective sensing of hepatitis C virus RNA. Chemistry. 2009;15:342-351.

18. Gaudy C, Thevenas C, Tichet J, et al. Usefulness of the hepatitis $C$ virus core antigen assay for screening of a population undergoing routine medical checkup. J Clin Microbiol. 2005;43:1722-1726.

19. Alivisatos P. The use of nanocrystals in biological detection. Nat Biotechnol. 2004;22:47-52.

20. Fortina P, Kricka LJ, Surrey S, et al. Nanobiotechnology: The promise and reality of new approaches to molecular recognition. Trends Biotechnol. 2005;23:168-173.

21. Pinaud F, King D, Moore HP, et al. Bioactivation and cell targeting of semiconductor $\mathrm{CdSe} / \mathrm{ZnS}$ nanocrystals with phytochelatin-related peptides. J Am Chem Soc. 2004;126:6115-6123.

22. Biju V, Itoh T, Anas A, et al. Semiconductor quantum dots and metal nanoparticles: Syntheses, optical properties, and biological applications. Anal Bioanal Chem. 2008;391:2469-2495.

23. Ghasemi Y, Peymani P, Afifi S. Quantum dot: Magic nanoparticle for imaging, detection and targeting. Acta Biomed. 2009;80:156-165.

24. Jun T, Bochu W, Liancai Z. Quantum Dots: A novel tool to discovery. Pak J Biol Sci. 2006;9:917-922.

25. William WY, Chang E, Drezek R, et al. Water-soluble quantum dots for biomedical applications. Biochem Biophys Res Comm. 2006;348:781-786.

26. Medintz IL, Mattoussi H, Clapp AR. Potential clinical applications of quantum dots. Int J Nanomedicine. 2008;3:151-167. 
27. Schröter S, Feucht M, Zöllner B, et al. Quantitative detection of hepatitis $\mathrm{C}$ virus RNA by light cycler PCR and comparison with two different PCR assays. J Clin Microbiol. 2001;39:3056-3059.

28. Bartolomé J, López-Alcorocho JM, Castillo I, et al. Ultracentrifugation of serum samples allows detection of hepatitis $\mathrm{C}$ virus RNA in patients with occult hepatitis C. J Virol. 2007;81:7710-7715.

29. Riccardi CS, Dahmouche K, Santilli CV, et al. Immobilization of streptavidin in sol-gel films: Application on the diagnosis of hepatitis C virus. Talanta. 2006;70:637-643.

30. Riccardi CS, Kranz C, Kowalik J, et al. Label-free DNA detection of hepatitis $\mathrm{C}$ virus based on modified conducting polypyrrole films at microelectrodes and atomic force microscopy Tip-integrated electrodes. Anal Chem. 2008;80:237-245.
31. Laemmli UK. Cleavage of structural proteins during the assembly of the head of bacteriophage T4. Nature. 1970;227:680-685.

32. Bradford M. A rapid and sensitive method for the quantitation of microgram quantities of protein utilizing the principle of protein-dye binding. Anal Biochem. 1976;72:248-254.

33. Lee Y, Lee EK, Cho YW, et al. ProteoChip: A highly sensitive protein microarray prepared by a novel method of protein immobilization for application of protein-protein interaction studies. Proteomics. 2003;3:2289-2304.
International Journal of Nanomedicine

\section{Publish your work in this journal}

The International Journal of Nanomedicine is an international, peerreviewed journal focusing on the application of nanotechnology in diagnostics, therapeutics, and drug delivery systems throughout the biomedical field. This journal is indexed on PubMed Central, MedLine, CAS, SciSearch $®$, Current Contents $\AA /$ Clinical Medicine,

\section{Dovepress}

Journal Citation Reports/Science Edition, EMBase, Scopus and the Elsevier Bibliographic databases. The manuscript management system is completely online and includes a very quick and fair peer-review system, which is all easy to use. Visit http://www.dovepress.com/ testimonials.php to read real quotes from published authors.

Submit your manuscript here: http://www.dovepress.com/international-journal-of-nanomedicine-journal 